8 Gerasimov B.N., Gerasimov K.B. Modeling the Development of Organization Management System // Asian Social Science. 2015. T. 11. № 20. C. 82-89.

9 Герасимов Б.Н., Герасимов К.Б. Управление экономическими системами. М.: ИНФРА-М, 2016. $225 \mathrm{c}$.

10 Герасимов Б.Н. Инновационный менеджмент. Самара: МГПУ, 2007. 298 с.

11 Кравченко В.Ф., Кравченко Е.Ф., Забелин П.В. Организационный инжиниринг. М.: ПРИОР, 1999. $256 \mathrm{c}$.

12 Герасимов Б.Н. Универсальная модель организационного реинжиниринга // Вестник Самарского государственного аэрокосмического университета. 2003.№ 2(4). С. 21-28.

13 Яковец Ю.В. Глобальные экономические трансформации XXI века. М.: Экономика, 2011. 382 с.

\title{
THE REFORM OF THE MANAGEMENT PROCESS INNOVATIONS OF THE ORGANIZATION
}

\author{
(C) 2020 Sultanova Alexandra Vasilievna \\ Candidate of economic Sciences, associate Professor \\ Samara state technical University \\ E-mail: sultanovaav@mail.ru
}

Keywords: organization, process, innovation management, structure, management tasks, feasibility of implementation.

In any organization, there are processes that play a special purpose. Most often, this type of process is innovation management. In connection with the existence of problems in the framework of this process the organization needs to reform its structure. The results of the implementation of the most important stages of reforming the organization's innovation management process are presented.

УДК 338

Код РИНЦ 06.00.00

\section{РАЗВИТИЕ ЧУВСТВА ВРЕМЕНИ У РУКОВОДИТЕЛЯ}

\author{
(C) 2020 Трошина Елена Павловна \\ кандидат экономических наук, доцент \\ Самарский государственный экономический университет \\ E-mail: e-troshina@yandex.ru
}

Ключевые слова: чувство времени, руководитель, компетенция, управление временем, метод.

Статья посвящена вопросу формирования одной из значимых личностных компетенций руководителя, а именно развитию чувства времени. Представлены методы, апробированные автором, позволяющие существенно повысить качество ежедневного планирования. Определены конкретные профессии, для которых необходимо активное развитие чувства времени. 
На сегодняшний день управление личным временем становится одной из наиболее важных задач для каждого конкретного человека. Это обосновывается тем, что от качества личностного планирования времени зависит эффрективность деятельности каждого отдельного человека. Особое значение управление своим временем приобретает для руководителей, это личностная компетенция не менее важна, чем профессиональные качества управленца.

Развитие чувства времени проявляется через составление различных планов на день, а также четкое их соблюдение. В процессе составления такого плана человек должен определить наиболее важные для себя задачи и длительность их реализации. Чаще всего такие планы получается реализовать не всегда, что связано с нереальностью числа включенных задач, а также неэффрективной само мотивацией.

Для построения профессиональной карьеры многим людям становится необходим инструмент реального планирования, позволяющего решить все поставленные задачи. Создание данного плана возможно только при условии развитого чувства времени, которое за счет соотношения задач и реального времени занятости, позволяет реализовать все запланированное. Таким образом, можно говорить о том, что чувство времени представляет собой особенное ощущение человека, позволяющее соотносить текущие дела и количество времени, реально существующего у человека, для их решения 1 .

Развитие чувства времени позволяет достичь достаточно больших результатов от любой деятельности, что приводит к важности и необходимости его развития. При этом за счет него создаются условия для последовательного решения поставленных задач. Это позволяет избежать лишней нервозности, суеты и спешки, а также работать более качественно и продуктивно.

Необходимость развития чувства времени обосновывается и тем, что оно позволяет минимизировать влияние стресса на человека за счет организации контроля. Данное положение обосновывается тем, что чувство времени позволяет распределять весь объем работы в течении дня, а, следовательно, снижать влияние стресса, возникающего изза опасения не выполнить работу в срок. Таким образом, чувство времени позволяет следить за уровнем нагрузки на человека, а также принимать наиболее эффективные решения в области оптимизации своей деятельности.

Иногда развитие чувства времени называют внутренними часами, позволяющими определить время без использования часов. Данное чувство можно и нужно развивать. Для этого сегодня создано достаточно большое количество инструментов и методов, которые на практике являются достаточно эфффективными.

Рассмотрим более детально основные методы развития чувства времени. Первым и наиболее популярным методом развития чувства времени является калибровка. Суть данного метода заключается в том, что для каждой конкретной задачи человек соотносит реальное время, отражаемое на часах, и планируемое время на выполнение задачи².

В процессе реализации задачи человек не смотрит на часы, а просто работает. По итогам завершения реализации задачи сравнивается плановое время на ее выполнение и фактическое. Данный метод позволяет существенно повысить качество ежедневного 
личностного планирования за счет более реальных сроков, закладываемых на реализацию той или иной задачи.

Описанный выше метод позволяет не только осуществлять более эффективное планирование, но и определить свое чувство времени. Так, если отличие планового времени на выполнение задачи от фактического колеблется в пределе 3 минут, то человек обладает достаточно хорошим чувством времени, а если времени на реализацию потребовалось больше планируемого времени на 5 минут, необходимо применять практики по развитию внутренних часов.

Другим методом, который используется в процессе развития чувства времени, является хронометраж. Реализация данного метода происходит с использованием таблицы, включающей в себя время начала работы над задачей, сущность задачи, а также время окончания работы над ней.

В течении всего дня человек заносит каждое реализованное дело, что позволяет не только обеспечить высокую эффективность личностного планирования, но и снять лишнюю нагрузку с мозга, поскольку он перестает думать о необходимости реализации той или иной задачи. Особенностью данного метода развития времени является то, что он переносит фокус с задачи на время, и чем чаще метод будет реализован, тем более качественно будет развиваться собственное чувство времени.

Ряд исследователей говорят о том, что эффективен метод хронометража и с использованием различных символов и сокращений. Особая эффективность такой реализации метода связана с сокращение времени на запись своих дел и задач.

Однако, данный метод достаточно сильно нагружает человеческий мозг. Это приводит к тому, что в начале его использования эффективным будет проведение записей два-три раза в неделю, после чего делается перерыв.

Такое использование метода позволяет равномерно распределить нагрузку на мозг человека и максимально увеличить планируемый от хронометража результат.

Отметим, что хронометраж дает большой качественный скачок в точности наших внутренних часов. Уже на первой-второй неделе человек реально изменяет политику своего расхода времени, начинает чувствовать его движение.

Эффективность применения данного метода обосновывается значительным количеством различных исследований. Так, за 4-6 недель человек фрормирует более 80\% точности своих внутренних часов, что позволяет существенно увеличить эффективность личностного планирования. На 7-8 неделю использования метода достигается более 90\% точности внутренних часов.

Развитие чувства времени в современных условиях является важной частью эффективности трудовой деятельности. В связи с этим оно особо актуально для людей, занятых в ведении собственного дела. Именно для них наблюдается высокий уровень стресса, поскольку они взваливают на себя все задачи по управлению и контролю деятельности своего предприятия. Особо актуально чувство времени и для различных руководителей, реализующих значительное число задач, которые бывают достаточно сильно трудоемкими. 
Рассматривая конкретные профессии, для которых необходимо активное развитие чувства времени, можно выделить:

- ИТ-специалистов;

- Работников образования;

- Работников творческих и спортивных профессий, поскольку они могут погружаться в свою деятельность, забывая о других задачах;

- Менеджеров различных звеньев и т.д.

Таким образом, можно говорить о том, что развитие чувства времени важно для любого человека. Это обосновывается тем, что от него зависит личностная и профессиональная эффективность каждого человека. При этом чувство времени позволяет достаточно эфффективно реализовать различные задачи, что также подтверждает важность внутренних часов 3 .

Чувство времени есть у каждого человека, однако степень его развития различна и зависит большей частью от рода деятельности. Методы развития чувства времени просты и доступны любому. Любой человек может повысить точность своих внутренних часов. Руководителю этому нужно уделять особое внимание, так как это влияет на осуществление его профессиональной деятельности.

1 Архангельский, Г. Тайм-драйв. Как успевать жить и работать / Глеб Архангельский. - М.: Манн, Иванов и Фербер, 2016. - 87 с.

2 Горбачев А.Г. Методы развития чувства времени. Электронный ресурс. Режим доступа: http://www.elitarium.ru/metody_razvitija_chuvstva_vremeni/

3 Шварц, Т. То, как мы работаем, - не работает. Проверенные способы управления жизненной энергией / Тони Шварц , Жан Гомес , Кэтрин Маккарти. - М.: Альпина Паблишер, 2016. - 320 с.

\section{DEVELOPING THE MANAGER'S SENSE OF TIME THE MAIN FACTORS INFLUENCING}

(C) 2020 Troshina Elena Pavlovna

Ph. D., associate Professor

Samara State University of Economics

E-mail: e-troshina@yandex.ru

Keywords: sense of time, Manager, competence, time management, method.

The article is devoted to the formation of one of the most important personal competencies of a Manager, namely, the development of a sense of time. The methods tested by the author are presented, which significantly improve the quality of daily planning. Specific professions that require the active development of a sense of time are identified. 